\title{
Health literacy and quality of life among Iranian pregnant women: The mediating role of health locus of control
}

\author{
Marjan Mirzania ${ }^{1}$, Abdoljavad Khajavi ${ }^{2}$, Akram Kharazmi $^{3}$, Mahdi Moshki*4 (D)
}

Received: 12 Mar 2019

Published: 1 Dec 2020

Abstract

Background: Main health challenge of the 21 st century is improving quality of life (QoL). This study aimed to investigate the mediating role of health locus of control (HLC) between health literacy and QoL among Iranian pregnant women.

Methods: In this cross sectional survey, 400 pregnant women referred to the community health centers of Gonabad, Iran, and completed the demographic, health literacy, QoL, and multidimensional HLC questionnaires during 2015-2016. Descriptive statistics and structural equation modeling were conducted using SPSS 22.0 version and AMOS 24.0 software.

Results: The findings showed that health literacy has a significant positive effect on the physical $(\beta=0.54, \mathrm{p}<0.001)$ and mental $(\beta=$ $0.57, p<0.001)$ health. Also, it has a significant positive effect on internal subscale $(\beta=0.42, p<0.001)$ and a significant negative effect on the chance $(\beta=-0.51, p<0.001)$ and powerful others $(\beta=-0.33, p<0.001)$ subscale of HLC. From HLC subscales, internal HLC had a significant positive effect on physical $(\beta=0.26, p<0.001)$ and mental $(\beta=0.12, p=0.010)$ health, while the effects of chance and powerful others on QoL dimensions were not significant. The findings indicated that internal HLC is a partial mediator between health literacy and physical dimension of QoL.

Conclusion: The results indicate that health literacy can be considered as an effective factor in HLC orientations and can improve QoL. This reflects the need for more attention on health literacy and the recognition of the type of HLC beliefs, especially the internal belief in health promotion programs for pregnant women.

Keywords: Health literacy, Quality of life, Locus of control, Pregnancy, Structural equation modelling

Conflicts of Interest: None declared

Funding: Gonabad University of Medical Sciences

\section{*This work has been published under CC BY-NC-SA 1.0 license. \\ Copyright $\odot$ Iran University of Medical Sciences}

Cite this article as: Mirzania M, Khajavi A, Kharazmi A, Moshki M. Health literacy and quality of life among Iranian pregnant women: The mediating role of health locus of control. Med J Islam Repub Iran. 2020 (1 Dec);34:161. https://doi.org/10.47176/mjiri.34.161

\section{Introduction}

Pregnancy is one of the most critical stages in a woman's life. This course, although pleasant to most women, is often considered a stressful period with physiological and mental changes. Even in a normal pregnancy, these changes can

Corresponding author: Prof. Mahdi Moshki,drmoshki@gmu.ac.ir

1. Department of Health Education and Promotion, School of Public Health, Tehran University of Medical Sciences, Tehran, Iran

2. Department of Social Medicine, School of Medicine, Gonabad University of Medical Sciences, Gonabad, Iran

3. Faculty of Nursing, Kashmar, Mashhad University of Medical Sciences, Mashhad, Iran

4. Department of Health Education and Promotion, School of Health; Social Development \& Health Promotion Research Center, Gonabad University of Medical Sciences, Gonabad, Iran affect the ability of every woman in performing her everyday-life roles and quality of life (QoL) (1).

Maintaining and promoting community health is an importan $t$ basis of community development. Modern health

$\uparrow$ What is "already known” in this topic:

Main health challenge of the 21st century is improving quality of life $(\mathrm{QoL})$. Health literacy and locus of control are recognized as the predictors of QoL. To the best of our knowledge, this is the first research that examines the mediating role of health locus of control (HLC) between health literacy and QoL.

\section{$\rightarrow$ What this article adds:}

Overall, the results of this study provide some support that HLC is a mediator between health literacy and QoL among Iranian pregnant women. Therefore, this result indicated the need for more attention to health literacy and the recognition of the type of HLC beliefs, especially the internal belief in health promotion programs. 
care has gradually shifted its focus from investigating mortality rate, as the health's outcome, to wider areas such as enhancing QoL (2). Also, over the past decade, the importance and the impacts of health literacy level on people's health have been considered. Low levels of health literacy can have negative outcomes, such as high hospitalization rates, high health costs, low QoL, and the risk of premature death (3). Health literacy includes the social and cognitive skills determining the motivation and the ability of individuals to access, perceive, and use information in ways that maintain and improve their health (4). The results of previous studies have shown a significant relationship between health literacy and QoL and have found people with adequate health literacy have a higher $\operatorname{QoL}(5,6)$.

Health locus of control (HLC) is recognized as a structure for perceiving and expressing health beliefs and behaviors and is defined as the degree of one's belief in the fact that his/her health is controlled by internal or external factors. Those with an external health locus of control (EHLC) believe that certain outcomes in their lives are controlled by factors, such as doctors, luck, fate, and fortune, while individuals with an internal health locus of control (IHLC) believe that their own actions and behaviors directly determine their health (7). Previous studies have indicated that there is a relationship between $\operatorname{IHLC}$ and $\operatorname{QoL}(8,9)$.

Health literacy and HLC have been suggested as the cognitive and mental predictors of health behaviors (10). The relationship between health literacy and HLC has been shown in some studies $(10,11)$. As Owens stated in a study, individuals with an IHLC and the higher levels of health literacy are more involved in health promotion behaviors (12). The results of Tsai et al's study showed health literacy has a positive relationship with IHLC and a negative relationship with EHLC (11). Health literacy is an important factor in improving access to health information and preventive care and reducing the overall health differences in individuals (13). Also, the QoL of each person is an important indicator in the assessment of health and medical status. Therefore, the lives of individuals can improve by providing appropriate information and improving the level of health literacy in the community (14). Maternal health literacy is an important concern for 2 reasons. First, women with low literacy face more challenges in learning new information. Second, the woman's health status and her perception of health information directly affect the child before pregnancy, during pregnancy, and during the years of development (15). Considering the importance of mothers' health literacy and that the type of HLC beliefs can predict pregnant women's health behaviors and have long lasting and highly significant effects on maternal and fetal health and also the impact of health literacy on QoL, this study aimed to investigate the mediating role of HLC between health literacy and QoL among Iranian pregnant women. We investigate this objective by determining the relationship between health literacy, HLC, and QoL and by examining the mediating role of HLC between health literacy and QoL.

\section{Methods}

This cross sectional survey was conducted on pregnant women who referred to the community health centers of Gonabad, northeast of Iran, from October 2015 to March 2016. Tabachnick and Fidell have recommended a minimum sample size of 300-400 as a general rule, based on the necessity of a sufficient sample size to perform valid factor analysis. (16) Since calculating sample size by considering the effect size suggested fewer samples than the number of samples required by the general rule (16), the number of samples was determined 420 according to a minimum of 350 samples and a dropout rate of $20 \%$. From 10 community health centers in Gonabad, 5 centers were randomly selected. Then, sampling was done from the selected centers by census method. The inclusion criteria of the study were as follow: age of at least 18 years, minimum reading and writing literacy, fetal health, and not having faced significant medical or obstetric problems before or during pregnancy. The exclusion criteria included preterm delivery and unwillingness to participate in the study. In the present study, 4 questionnaires were not complete and 16 had more than $20 \%$ missing data, which were excluded from the final analyses (response rate: 95.2\%).

\section{Instruments}

Demographic information: The questionnaire consisted of the items on age, age at marriage, the age of pregnancy, education level, occupation, economic status, the number of pregnancies, and the type of pregnancy (wanted or unwanted).

Health literacy of Iranian adults (HELIA): The questionnaire consists of 33 items under the 5 subscales of access (6 items), reading (4 items), understanding ( 7 items), assessment (4 items), and decision (12 items). It consists of 5point Likert items, ranging from 0 to 4 (always $=4$, often $=$ 3 , sometimes $=2$, rarely $=1$, and never $=0$ ). Therefore, the health literacy score of each sample would be between 0 and 132, which is divided into 3 classes of inadequate (0$80)$, marginal (81-101), and adequate (102-132) based on the cut points of 80 and 101 . The construct validity of this scale was evaluated by exploratory factor analysis (EFA) and its reliability by internal correlation coefficient. The results of EFA showed the questionnaire had desirable construct validity and explained $53.2 \%$ of the variance. Also, Cronbach's alpha coefficient has been reported to fall between the range of 0.72 to 0.89 , which confirms the validity and the reliability of the questionnaire (17).

Short-Form health survey (SF-36): This questionnaire consists of 36 items, which investigate the health status through the 8 subscales of physical functioning (PF-10 items), role physical (RP-4 items), bodily pain (BP-2 items), general health perceptions (GH-5 items), vitality (VT-4 items), social functioning (SF-2 items), role emotional (RE-3 items), and perceived mental health (MH-5 items). Also, 3-choice questions (scores: 0, 50, 100), 5choice questions (scores: $0,25,50,75,100), 6$-choice questions (scores: 0, 20, 40, 60, 80, 100) were intended. The scores for each subscale vary from zero to 100 , and a higher score indicates better performance. The validity and reliability of this scale were confirmed and the results of EFA explained $85 \%$ of the variance (18). Also, the validity and reliability of the Persian version have been approved with 
the Cronbach's alpha coefficient ranging from 0.77 to 0.90 (19).

Multidimensional health locus of control (MHLC) scales: This questionnaire has been designed to evaluate people's health beliefs and has the 3 forms of A, B, and C. Form B has been used in the present study. This form consists of 18 items under the 3 subscales of IHLC, PHLC (the belief that one's health is determined by other individuals), and CHLC (the belief that one's health depends on luck, fate, and destiny). The questionnaire consists of 6-point Likert items, which are scored from 1 to 6 . As a result, one's score may vary from 6 to 36 for each subscale, which will not be summed up and each item would be estimated independently (7). The scale has reported Cronbach's alpha coefficient ranging from 0.60 to 0.75 and test-retest reliability ranging from 0.60 to $0.70(20)$. The validity and the reliability of the Persian version of the questionnaire have been confirmed, with the Cronbach's alpha coefficient ranging from 0.69 to 0.72 and the parallel form reliability between 0.70 to 0.72 for C, P and I subscales, respectively (21).

\section{Statistical analysis}

The data were analyzed using SPSS 22 version (IBM Corp, Armonk, NY, USA) and AMOS 24.0 software. Prior to beginning the analysis, missing data were estimated using the median method. The relationship between the research variables was investigated using Pearson correlation analysis. Structural equation modeling (SEM) was performed to assess the mediation effects by using the maximum likelihood estimation method. The measurement model was examined through confirmatory factor analysis and evaluating goodness-of-fit indices. Some of these indices and their desirable values are as follow: The normed chi-square $(\mathrm{CMIN} / \mathrm{DF})<3$; root mean square error of approximation (RMSEA) $<0.08$; goodness-of-fit index (GFI) and adjusted goodness-of-fit index (AGFI), which should be less than 0.80; parsimonious normed fit index (PNFI), which should be more than 0.5 ; normed fit index (NFI), and Tucker-Lewis index (TLI), comparative fit index (CFI), relative fit index (RFI), and incremental fit index (IFI), which should be $\geq 0.99(22,23)$. The significance level was set as $\mathrm{p}<0.05$.

The mediation analysis was performed using bootstrap- ping method with 2000 samples to assess the indirect effects of health literacy on QoL through HLC subscales. Bootstrapping is a nonparametric distribution method that allows the estimation of standard error and the confidence interval of mediation effects (24). The hypothetical model is shown in Figure 1.

\section{Ethical consideration}

This study was approved by the ethical committee of Gonabad University of Medical Sciences (ethical code: IR.GMU.REC.1396.619). The research goals were clearly and precisely described to the participants and their informed consent was obtained.

\section{Results}

The mean age of participants was $27.2 \pm 5.40$ years and their mean age of marriage was $75.52 \pm 56.02$ months. Other basic characteristics of participants are reported in Table 1.

The mean, standard deviation, and the results of Pearson correlation analysis for investigating the relationship between health literacy, HLC subscales (I, C, and P), and QoL dimensions (physical and mental health) are presented in Table 2. The results showed that participants had an adequate level of health literacy $(104.04 \pm 14.42)$. Among the subscales of HLC, the IHLC (30.32 \pm 3.62$)$ and among QoL dimensions, mental health $(74.08 \pm 13.61)$ had the highest scores. The results also showed health literacy has a significant negative relationship with CHLC $(\mathrm{r}=-0.388, \mathrm{p}<$ $0.01)$ and PHLC $(r=-0.239, p<0.01)$, while having a significant positive relationship with IHLC $(\mathrm{r}=0.364, \mathrm{p}<$ $0.01)$, physical $(\mathrm{r}=0.393, \mathrm{p}<0.01)$ and mental health $(\mathrm{r}=0.409, \mathrm{p}<0.01)$. IHLC has a significant positive relationship with physical $(\mathrm{r}=0.351, \mathrm{p}<0.01)$ and mental health $(r=0.390, p<0.01)$, while physical health has a significant negative relationship with CHLC and PHLC $(r=-$ 0.334 and $r=-0.213$, respectively, $p<0.01$ ). Mental health also had significant negative relationships with CHLC and PHLC $(r=-0.332$ and $r=-0.179$, respectively, $\mathrm{p}<0.01)$.

The evaluation of the measurement model using confirmatory factor analysis showed fit indices do not have acceptable values. Then, the post hoc model modifications were used to improve the fit, based on modification indices. The results showed all fit indices have improved and are acceptable (Table 3).

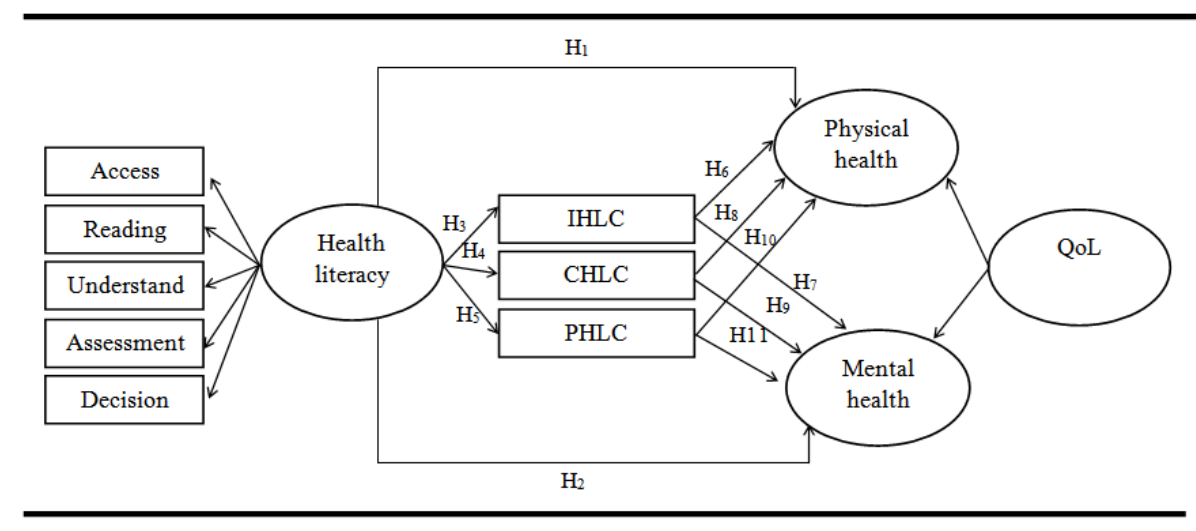

Fig. 1. Theoretical model and hypotheses 


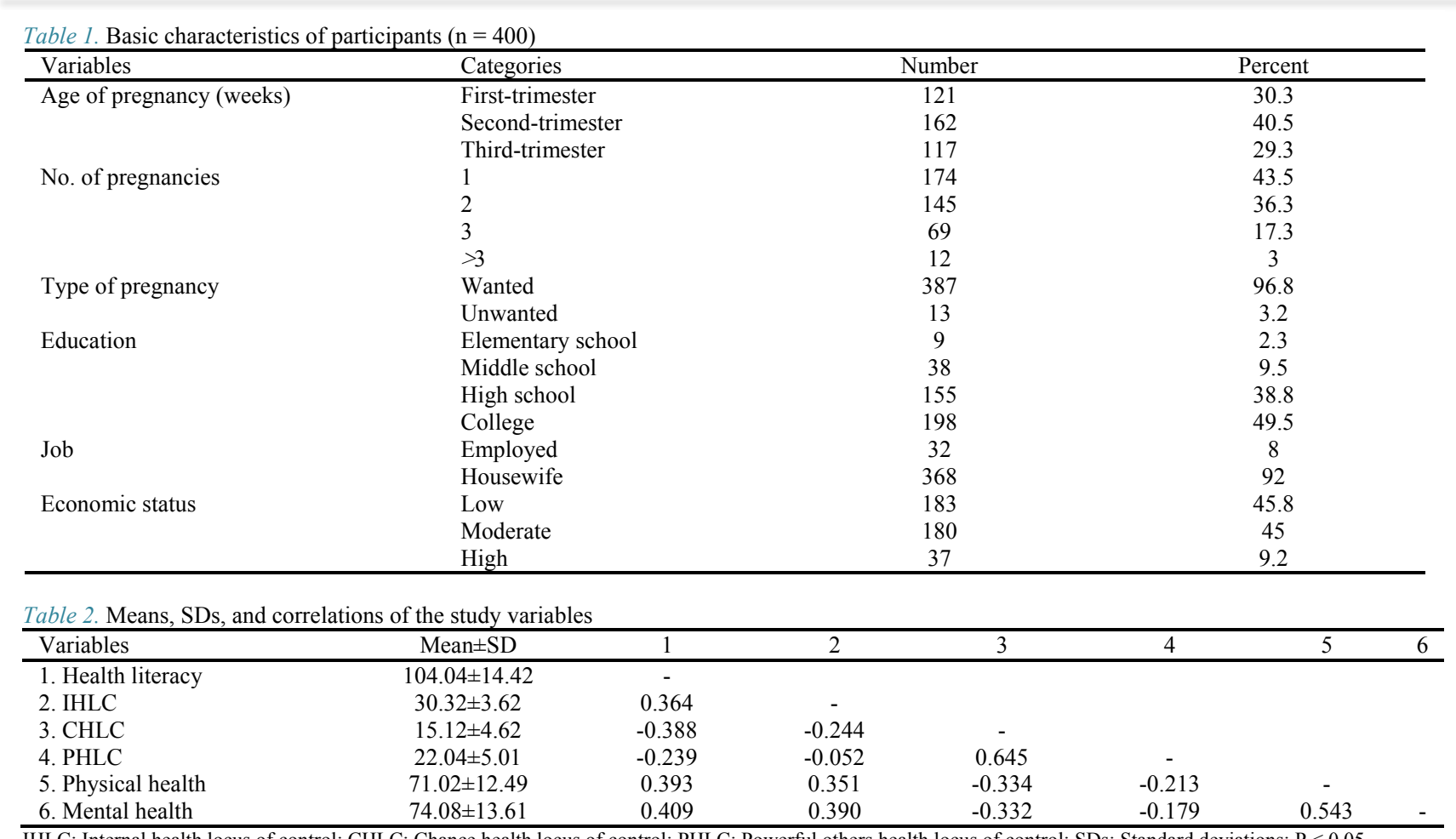

IHLC: Internal health locus of control; CHLC: Chance health locus of control; PHLC: Powerful others health locus of control; SDs: Standard deviations; P $<0.05$.

Table 3. Summary of the CFA goodness-of-fit fit indices for models

\begin{tabular}{lccccccccccc}
\hline Models & CMIN/DF & RMSEA & PNFI & GFI & AGFI & NFI & TLI & CFI & RFI & IFI \\
\hline First model fitted & 4.354 & 0.092 & 0.626 & 0.886 & 0.838 & 0.782 & 0.776 & 0.821 & 0.728 & 0.823 \\
Second model fitted & 2.368 & 0.059 & 0.686 & 0.937 & 0.907 & 0.885 & 0.909 & 0.929 & 0.852 & 0.930 \\
\hline
\end{tabular}

In the structural model, the research hypotheses were tested. The obtained results are shown in Figure 2 and Table 4. According to the results, health literacy with path coefficient of 0.541 and 0.577 and a confidence level of $99 \%$ has a significant positive effect on physical and mental health. In addition, the effect of health literacy on I, C, and P sub- scales at the confidence level of $99 \%$ was positive, negative, and negative, respectively $(\beta=0.428, \beta=-0.515, \beta$ $=-0.335, \mathrm{p}<0.001)$. The path coefficient for the impact of HLC on QoL showed the IHLC, with path coefficient of 0.265 and 0.125 at the confidence level of $99 \%$, has a significant positive effect on physical and mental health. How-

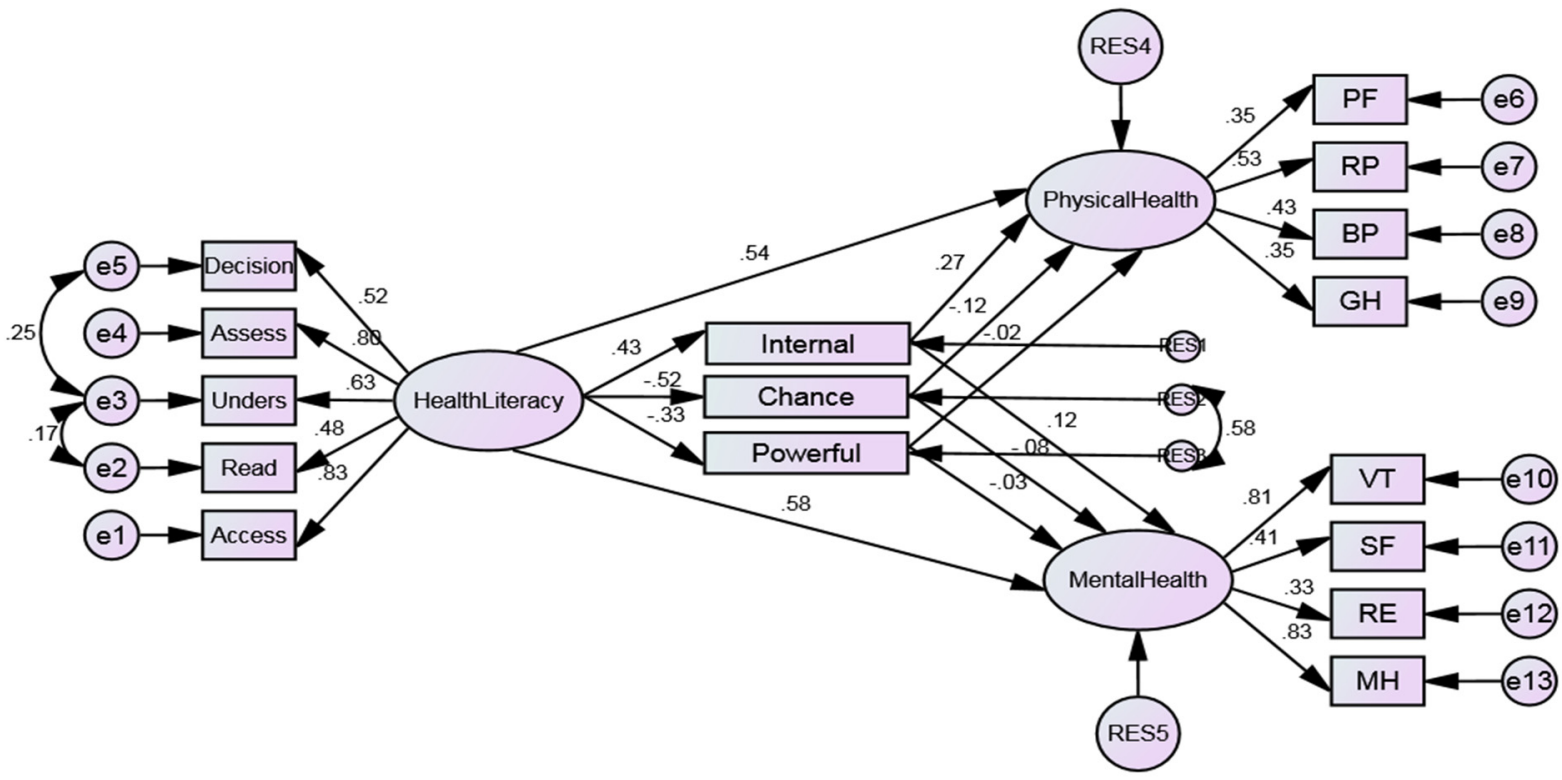

Fig. 2. Results of structural equation modeling analysis 


\begin{tabular}{|c|c|c|c|c|}
\hline Hypotheses & Structural path & $\mathrm{PC}$ & $\mathrm{p}$ & Supported \\
\hline$\overline{\mathrm{H}_{1}}$ & Health literacy $\rightarrow$ Physical health & 0.541 & $<0.001$ & Yes \\
\hline $\mathrm{H}_{2}$ & Health literacy $\rightarrow$ Mental health & 0.577 & $<0.001$ & Yes \\
\hline $\mathrm{H}_{3}$ & Health literacy $\rightarrow$ IHLC & 0.428 & $<0.001$ & Yes \\
\hline $\mathrm{H}_{4}$ & Health literacy $\rightarrow$ CHLC & -0.515 & $<0.001$ & Yes \\
\hline $\mathrm{H}_{5}$ & Health literacy $\rightarrow$ PHLC & -0.335 & $<0.001$ & Yes \\
\hline $\mathrm{H}_{6}$ & IHLC $\rightarrow$ Physical health & 0.265 & $<0.001$ & Yes \\
\hline $\mathrm{H}_{7}$ & IHLC $\rightarrow$ Mental health & 0.125 & $<0.05$ & Yes \\
\hline $\mathrm{H}_{8}$ & CHLC $\rightarrow$ Physical health & -0.118 & 0.214 & No \\
\hline $\mathrm{H}_{9}$ & CHLC $\rightarrow$ Mental health & -0.078 & 0.242 & No \\
\hline $\mathrm{H}_{10}$ & PHLC $\rightarrow$ Physical health & -0.022 & 0.786 & No \\
\hline $\mathrm{H}_{11}$ & PHLC $\rightarrow$ Mental health & -0.026 & 0.654 & No \\
\hline
\end{tabular}

IHLC: Internal health locus of control; CHLC: Chance health locus of control; PHLC: Powerful others health locus of control; PC: Path coefficients.

\begin{tabular}{|c|c|c|c|c|c|c|c|}
\hline \multirow[t]{2}{*}{ Structural path } & \multicolumn{2}{|c|}{ Total effects } & \multicolumn{2}{|c|}{ Direct effects } & \multicolumn{2}{|c|}{ Indirect effects } & \multirow[t]{2}{*}{ Results } \\
\hline & $\mathrm{PC}$ & $\mathrm{p}$ & $\mathrm{PC}$ & $\mathrm{p}$ & $\mathrm{PC}$ & $\mathrm{p}$ & \\
\hline Health literacy $\rightarrow$ IHLC $\rightarrow$ Physical health & 0.733 & 0.001 & 0.619 & 0.001 & 0.113 & 0.002 & Partial mediation \\
\hline Health literacy $\rightarrow$ IHLC $\rightarrow$ Mental health & 0.687 & 0.001 & 0.629 & 0.001 & 0.053 & 0.141 & No mediation \\
\hline
\end{tabular}

IHLC: Internal health locus of control; PC: Path coefficients.

ever, the impact of CHLC and PHLC subscales was not significant on physical and mental health. Model's explanatory power was evaluated according to $\mathrm{R}^{2}$ values and was 0.184 for IHLC, 0.265 for CHLC, 0.112 for PHLC, and 0.594 and 0.481 for physical and mental health, respectively. These values indicate that $18 \%, 26 \%$, and $11 \%$ of the variance in I, C, and PHLC respectively, are explained by health literacy. Moreover, $59 \%$ of the variance in physical health and $48 \%$ in mental health were explained by health literacy and HLC.

As the impact of CHLC and PHLC subscales on physical and mental health was not significant, they were excluded from mediation analyses, and the mediating role of IHLC subscale between the health literacy and QoL dimensions was investigated. According to the results shown in Table 5 , the overall effect, direct effect, and indirect effect of health literacy on physical health was significant through IHLC, while the indirect impact of health literacy on mental health was not significant through IHLC. Therefore, it can be inferred that the IHLC is only a partial mediator between health literacy and the physical health dimension of QoL.

\section{Discussion}

The results of this study provide some support that HLC is a mediator between health literacy and QoL among Iranian pregnant women. To the best of our knowledge, this is the first research that examines the mediating role of HLC between health literacy and QoL.

The findings of this study reveal a significant positive relationship between health literacy and physical and mental health dimensions of the QoL. Previous studies confirm these results and show that lower levels of health literacy are associated with lower physical and mental health (25). Furthermore, the findings indicate that IHLC has a significant positive relationship with physical and mental health, while CHLC and PHLC have significant negative relationships with physical and mental health. In fact, individuals with higher IHLC believe they have the power of choice to improve their QoL and their actions control their fate and outcomes, which is why they are more likely to show a higher level of QoL. While individuals with higher EHLC do not directly consider themselves to be responsible for their own health and always believe in the external factors regarding their diseases or health. Therefore, they have a feeling of incapability and lack of control over their position, which results in a lower QoL $(26,27)$. These findings are consistent with previous studies (28-30). In addition, the findings of the present study show health literacy has a significant positive relationship with IHLC and a significant negative relationship with CHLC and PHLC. These findings support previous researches indicating that the higher level of IHLC and the lower levels of CHLC and PHLC may be associated with higher health literacy (10, 31).

In this study, health literacy has a significant positive effect on the physical and mental health dimension of QoL. Son et al also showed health literacy is a predictor of QoL and adequate health literacy is an important factor in improving the QoL in patients (32). Moreover, the findings of the current study show health literacy has a significant positive effect on IHLC and a significant negative impact on CHLC and PHLC. On the other hand, among HLC subscales, only the IHLC has a significant positive effect on physical and mental health, while the effects of CHLC and PHLC on physical and mental health are not significant. The results of the studies also show that the locus of control is a predictor of QoL and more internal locus of control results in higher QoL, while the external locus of control has a negative impact on QoL $(30,33)$.

Finally, assessing the mediating role of HLC between health literacy and QoL showed the IHLC plays a partial mediating role between health literacy and the physical dimension of QoL. In fact, people with higher levels of health literacy are more inclined to IHLC than those with lower levels of health literacy. (10) These people rely on their own skills and abilities and have control over their emotions, behaviors, and living conditions and associate their positions and failures with internal factors. They believe they are in control of their QoL and health status (34). However, the findings of this study do not confirm the mediating role of other HLC subscales ( $\mathrm{C}$ and $\mathrm{P}$ ) between health literacy and the dimensions of QoL. 
There are obvious limitations that should be considered while interpreting the results. First, the cross sectional approach of the study limits the generalizability of the results. Second, the samples cannot represent the pregnant women population in terms of cultural and social diversity; perhaps different factors such as ethnicity, customs, traditions, and beliefs of pregnant women can affect their QoL and HLC.

\section{Conclusion}

Health literacy functions as an effective factor in HLC orientations in pregnant women. Thus, pregnant women with higher levels of health literacy are more inclined toward IHLC and their type of belief (internal) also greatly affects their QoL. Therefore, the results of this study indicated the need for more attention to health literacy and the recognition of the type of HLC beliefs, especially the internal belief in health promotion programs for pregnant women.

\section{Acknowledgment}

Our deep gratitude to the officials at the Social Development \& Health Promotion Research Center, Gonabad University of Medical Sciences, and all those mothers who made this research possible with their participation.

\section{Conflict of Interests}

The authors declare that they have no competing interests.

\section{References}

1. Abbaszadeh F, Baghery A, Mehran N. Quality of life among pregnant women. Hayat. 2009;15(1):41-48.

2. Lee CF, Chien LY, Ko YL, Chou YH, Tai CJ, Liou YM. Development and psychometric properties of the Chinese language version of the TAPQOL: A health-related quality of life instrument for preschool children. Int J Nurs Stud. 2005;42(4):457-465.

3. Wilson K. An exploration of older adult's health literacy experiences: A grounded theory study. Dissertation University of Phoenix; 2010.

4. Downey LV, Zun LS. Assessing adult health literacy in urban healthcare settings. J Natl Med Assoc. 2008;100(11):1304-1308.

5. Macabasco-O'Connell A, DeWalt DA, Broucksou KA, Hawk V, Baker DW, Schillinger D, et al. Relationship between literacy, knowledge, self-care behaviors, and heart failure-related quality of life among patients with heart failure. J Gen Intern Med. 2011;26(9):979986.

6. Nesbitt T, Doctorvaladan S, Southard JA, Singh S, Fekete A, Marie $\mathrm{K}$, et al. Correlates of quality of life in rural patients with heart failure. Circ Heart Fail. 2014;7(6):882-887.

7. Wallston KA, Wallston BS, DeVellis R. Development of the Multidimensional Health Locus of Control (MHLC) scales. Health Educ Monogr. 1978;6(2):160-70.

8. Theofilou P. Quality of life and mental health in hemodialysis and peritoneal dialysis patients: the role of health beliefs. Int Urol Nephrol. 2012;44(1):245-253.

9. Koplas PA, Gans HB, Wisely MP, Kuchibhhatla M, Cutson TM, Gold DT, et al. Quality of life and Parkinson's disease. J Gerontol A Biol Sci Med Sci. 1999;54(4):197-202.

10. Tsai TI, Lee SYD, Tsai YW. Health literacy, self-efficacy, health locus of control, and health-related behaviors in Taiwan. Conference: 140st APHA Annual Meeting and Exposition 2012.

11. Tsai TI, Lee SYD, Tsai YW. Explaining selected health behaviors in a national sample of Taiwanese adults. Health Promot Int 2015;30(3):563-572.

12. Owens L. The relationship of health locus of control, self-efficacy, and health promoting in older Adults .dissertation. Univercity of Memphis; 2006.

13. Amiresmaili M, Nekoei Moghadam M, Saberi anari SH, Sadeghi A,
Saber M, Taheri G, et al. Study of health literacy level of women referring to health centers-2010. J North Khorasan Univ Med Sci. 2014;5(5):1071-1078.

14. Khodabakhshi-Koolaee A, Bahari M, Falsafinejad MR, Shahdadi H. The relationship of quality of life with health literacy in male patients with Type II Diabetes: A cross-sectional Study in Harsin City 2015. J Diabetes Nurs. 2016;4(4):10-20.

15. Ghanbari S, Majlessi F, Ghaffari M, Mahmoodi Majdabadi M. Evaluation of health literacy of pregnant women in urban health centers of Shahid Beheshti Medical University. Daneshvar Med. 2012;19(97):112.

16. Tabachnick B G, Fidell L S. Using Multivariate Statistics. Pavithra Jayapaul/Jouve; 2013.

17. Montazeri A, Tavousi M, Rakhshani F, Azin SA, Jahangiri K, Ebadi $\mathrm{M}$, et al. Health Literacy for Iranian Adults (HELIA): Development and psychometric properties. Payesh. 2014;13(5):589-600.

18. Ware JE, Sherbourne CD. The MOS 36-Item Health Survey (SF36). I. Conceptual framework and item selection. Med Care. 1992;30(6):473-483.

19. Montazeri A, Goshtasebi A, Vahdaninial M, Gandek B. The Short Form Health Survey (SF-36): Translation and validation study of the Iranian version. Qual Life Res. 2005;14(3):875-882.

20. Wallston KA. The validity of multidimensional health locus of control scales. J Health Psychol. 2005;10(5):623-631.

21. Moshki M, Ghofranipour F. Iranian version of form B of the multidimensional health locus of control scales among the youth. J Clin Nurs. 2011; 20(11-12):1561-1567.

22. Kline RB. Principles and practice of structural equation modeling. New York: Guilford Press; 2011.

23. Awang Z. SEM made simple: A gentle approach to learning structural equation modeling. Malaysia: MPWS Rich Publication, Bangi; 2015.

24. Hayes AF. Introduction to mediation, moderation, and conditional process analysis: a regression-based approach. Guilford Press; 2013.

25. Jayasinghe UW, Harris MF, Parker SM, Litt J, Driel M, Mazza D, et al. The impact of health literacy and life style risk factors on healthrelated quality of life of Australian patients. Health Qual Life Outcomes. 2016;14(68):1-13.

26. Sharif SP. Locus of control, quality of life, anxiety, and depression among Malaysian breast cancer patients: The mediating role of uncertainty. Eur J Oncol Nurs. 2017;27:28-35.

27. Fiori KL, Brown EE, Cortina KS, Antonucci TC. Locus of control as a mediator of the relationship between religiosity and life satisfaction: Age, race, and gender differences. Ment Health Relig Cult. 2006;9(3):239-263.

28. Sengul Y, Kara B, Arda MN. The relationship between health locus of control and quality of life in patients with chronic low back pain Turk Neurosurg. 2010;20(2):180-185.

29. Brown AJ, Sun CC, Urbauer DL, Bodurka DC, Thaker PH, Ramondetta LM. Feeling powerless: Locus of control as a potential target for supportive care interventions to increase quality of life and decrease anxiety in ovarian cancer patients. Gynecol Oncol. 2015;138(2):388-393.

30. Sharif SP, Khanekharab J. External locus of control and quality of life among Malaysian breast cancer patients: The mediating role of coping strategies. J Psychosoc Oncol. 2017;35(6):706-725.

31. Okubo S, Iino S, Sawada Y, Sugimoto Ch, Dono M, Akagawa A Correlation between health literacy, health locus of control, and healthrelated activities and healthy weight in community residents. J Soc Nurs Pract. 2014;26(1):23-31.

32. Son YJ, HY Yu. Influence of health literacy on HRQoL in Patients After PCI. West J Nurs Res. 2016;38(12):1611-1626.

33. Ghasemizad AR, Berenjian Tabrizi H, Abedi MR, Barzideh O. A study of the relationship among Fars shahed and esargar high school students quality of life, self-esteem, locus of control, stress and social capital. Quart J New Approach Educ. 2011;1(4):107-123.

34. Hassanzadeh R, Toliati SM, Hosseini SH, Davari F. Relationship between health control of control and health behaviors. Iran J Psychiatry Clin Psychol. 2006;12(3):277-281. 